\title{
The impact of intrahepatic cholestasis of pregnancy on fetal cardiac and peripheral circulation
}

\author{
Seçil Kurtulmuş ${ }^{1}$, Esra Bahar Gür², Deniz Öztekin ${ }^{3}$, Ebru Şahin Güleç3, Duygu Okyay ${ }^{3}$, İbrahim Gülhan ${ }^{3}$ \\ 'Department of Obstetrics and Gynecology, Kâtip Çelebi University Faculty of Medicine, Izmir, Turkey \\ ${ }^{2}$ Department of Obstetrics and Gynecology, Şifa University Faculty of Medicine, Izmir, Turkey \\ ${ }^{3}$ Department of Obstetrics and Gynecology, Aegean Maternity and Teaching Hospital, Izmir, Turkey
}

\section{Abstract}

Objective: The aim of this study was to evaluate changes in fetal cardiac and peripheral circulation in pregnancies complicated with intrahepatic cholestasis.

Material and Methods: The Doppler examination results of 22 pregnant subjects complicated with intrahepatic cholestasis of pregnancy (ICP) and 44 healthy controls were compared. The parameters of fetal cardiac circulation were pulmonary artery and aortic (Ao) peak systolic velocity (PSV), pulmonary vein (Pv), peak velocity index (PVI) and pulsatility index (PI), mitral valve (MV) and tricuspid valve (TV), early diastole (E)- and atrial contraction (A)-wave peak velocity ratio (E/A), and isthmus aortic peak systolic velocity (IAo PSV). The parameters of fetal peripheral circulation were middle cerebral artery (MCA) and umbilical artery (UA) PI, resistance index (RI), systolic/diastolic (S/D) ratio. Fetal obstetric Doppler monitoring was conducted weekly before 36 weeks and biweekly after that, and the results were compared with the normal reference values for gestational age.

Results: The Doppler parameters of fetal cardiac and peripheral circulation did not significantly differ between the two groups. S/D ratio readings in the ICP group were significantly above $2 \mathrm{SD}$ before 35 weeks of gestation. Women with ICP had increased risks of preterm delivery, neonatal unit admission, and meconium-stained amniotic fluid compared with those in the controls.

Conclusion: Fetuses of pregnant women with ICP showed no differences in the evaluation of cardiac and peripheral Doppler measurements compared with fetuses of healthy mothers. The Doppler investigation of the umbilical artery may be useful in monitoring of pregnancies complicated by early onset intrahepatic cholestasis. (J Turk Ger Gynecol Assoc 2015; 16: 74-9)

Keywords: Intrahepatic cholestasis of pregnancy, fetal Doppler, fetal cardiac circulation

Received: 14 October, 2014

Accepted: 18 January, 2015

\section{Introduction}

The characteristic features of intrahepatic cholestasis of pregnancy (ICP) include abnormal liver function and maternal pruritus that most frequently occur in the third trimester. Adverse fetal outcomes such as spontaneous pre-term labor, fetal distress, and even intrauterine death are frequently associated with ICP (1-3). The pathophysiology and epidemiology of fetal morbidity are not well characterized. Intrauterine death may occur without prior symptoms, such as uteroplacental insufficiency or intrauterine growth restriction, with no significant findings during fetal autopsy $(4,5)$. Non-specific pathology suggestive of hypoxia has been reported in placental histological samples; however, hypoxia has not been established as a primary pathophysiological process in ICP (6). Several studies have reported that fetal complications of ICP occur more commonly in pregnancies where the mother displays elevated levels of serum bile acids $(7,8)$. It is postulated that raised levels of fetal serum bile acids may be cardiotoxic to the fetus (9). There are currently no methods present for predicting the risks for the fetus in pregnancies complicated with ICP.
Abnormal heart rate ( $\leq 100$ or $\geq 180 \mathrm{bpm}$ ) is associated with an elevated risk in some studies, although cardiotocograph monitoring cannot reliably predict the risk of complications, and normal cardiotographs are observed within $24 \mathrm{~h}$ of intrauterine demise (10-12). Furthermore, fetal heart rate tracing does not correlate with disease severity (13). The results of a study using the fetal biophysical profile and obstetric Doppler examination findings were not conclusive, mainly because of the absence of fetal mortality and morbidity in that series (14). However, there is very little information about whether changes of fetal cardiac Doppler parameters present in pregnancies complicated with ICP. The aim of this study was to evaluate whether some Doppler alterations exist at the examination of fetal cardiac and peripheral circulation in pregnancies complicated with ICP and to compare them with healthy pregnancies.

\section{Material and Methods}

This observational study was conducted with the approval of the Ethical Committee of Aegean Maternity and Teaching 
Hospital, and the procedures followed were in accordance with the Declaration of Helsinki of 1975 (revised in 2008). All study participants provided informed consent.

The study was conducted in the clinic of Aegean Maternity and Teaching Hospital between January 2013 and January 2014. During the study period, there were 4037 normal vaginal and 2987 cesarean section deliveries, and 94 pregnant women with ICP were admitted to our hospital. The criteria that were used for diagnosing ICP were raised levels of serum bile acids (total bile acid level was $\geq 10 \mu \mathrm{mol} / \mathrm{L}$ ) and/or pruritus coinciding with liver dysfunction during the third trimester (29-40 weeks), and the absence of skin lesions, and resolution of these symptoms following delivery. Elevated levels of liver alanine transaminase (ALT) and aspartate transaminase (AST) were used to confirm the diagnosis. Liver transaminase results exceeding $40 \mathrm{IU} / \mathrm{L}$ were considered abnormal (15, 16). Abnormal liver function tests were followed-up with viral marker testing and liver ultrasonography. The presence of biliary obstruction or gallstones during liver ultrasound or acute infection with hepatitis $\mathrm{A}, \mathrm{B}$, or $\mathrm{C}$ precluded the diagnosis of obstetric cholestasis. A medical history including pruritus in a prior pregnancy, outcome of prior pregnancies, skin disorders, liver/gall-bladder disorders, and use of oral contraceptives was obtained. For both patients and control subjects, exclusion criteria consisted of known multiple gestation, systemic lupus erythematosus, age $<18$ and $>40$ years, and fetuses with a known cardiac anomaly or arrhythmia. Additional causes of liver dysfunction, including hemolysis, elevated liver enzymes and low platelets syndrome, preeclampsia, primary biliary cirrhosis, acute fatty liver, and progesterone or any other medications were considered as criteria for exclusion from the study. The presence of confounding characteristics including intrauterine growth retardation (fetal weight below $10^{\text {th }}$ percentile) and oligohydramnios (amniotic fluid index $<50$ ) were also considered as criteria for exclusion.

Serum AST and ALT levels were measured using Roche methods on a Hitachi 917 Analyzer (Roche Diagnostics, Basel, Switzerland). Total levels of serum bile acids were analyzed with an enzymatic, colorimetric method (Enzabile, Biostat Diagnostic Systems, Stockport, UK).

Ursodeoxycholic acid (UDCA $2 \times 300 \mathrm{mg}$ daily) was provided to all patients when the diagnosis of ICP was confirmed. The daily dosage of UDCA was further increased up to $900 \mathrm{mg}$ or to a maximum of $1.500 \mathrm{mg}$ for patients with severe symptoms. Twenty-two pregnant women with ICP were found to be in compliance with the criteria of the study period. For each case, two healthy pregnant controls were matched for maternal age and gestational age at ultrasound ( \pm 1 week). An a priori sample size calculation was performed with an $\alpha$ value of 0.05 and a $\beta$ value of 0.20 based on the estimated umbilical artery systolic/diastolic (UA S/D) ratio of $2.64 \pm 0.49$ between 34 and 37 gestational weeks. It was estimated that a total sample size of 20 pregnant women would be required to reveal a difference of 0.5 in the UA S/D ratio between the two groups. Therefore, we observed that the number of patients that we evaluated during the study period was sufficient for analysis.

\section{Sonographic examinations}

A color Doppler unit (Toshiba Aplio 500, Tokyo, Japan) with a 3.5-MHz convex probe was used to perform all ultrasonographic measurements. Gestational age was determined based on fetal measurements and the date of last menstruation. The presence of congenital heart abnormalities was excluded by the ultrasonographic evaluation of fetal cardiac anatomy.

The angle of the transducer beam relative to the direction of blood flow was maintained at $<20^{\circ}$ throughout Doppler ultrasonography, and the high-pass filter was set at $100 \mathrm{~Hz}$. All cardiac parameters were evaluated over 3-5 consecutive cardiac cycles and were stored for off-line analysis; a single investigator (S.K.) completed all measurements. All measurements were obtained in the absence of uterine contractions, fetal breathing, or other fetal movements, and the mother was positioned in the left lateral recumbent position.

The Doppler measurement of UA was conducted at the umbilical cord midsection. Insonation of the middle cerebral artery (MCA) occurred via the occipital or temporal bone window identified by the circle of Willis on the axial section of the brain. Resistance index (RI), pulsatility index (PI), and S/D ratio were evaluated for both UA and MCA.

The isthmus aortic peak systolic velocity (IAo PSV) was measured from either the sagittal longitudinal aortic view or three vessel trachea view with an insonation angle $<30^{\circ}$. The atrioventricular valves were imaged from the apical four-chamber view of the heart. Two diastolic peaks were used to characterize flow velocity at the tricuspid valve (TV) and mitral valve (MV), corresponding to active ventricular filling during atrial contraction (A-wave) and early ventricular filling (E-wave). The E/A ratio was calculated from the E-wave and A-wave peak velocities.

The pulmonary veins (PV) were visualized by color Doppler imaging, following the four-chamber cross-section imaging of the fetal heart and thoracic cavity. Sample volumes were placed above PV immediately dorsal to the entrance into the left atri$\mathrm{um}$. The angle of the ultrasound beam relative to the direction of blood flow was maintained at $<10^{\circ}$, and PI and peak velocity Index (PVI) were evaluated.

The study included patients admitted to the hospital with the diagnosis of ICP, and according to our hospital protocol, UDCA treatment was initiated to all patients. For this reason, Doppler sonographic assessment was performed on the ICP group after the administration of UDCA, and it was not possible to assess the effect of UDCA on Doppler parameters.

Fetal Doppler examination for cardiac circulation was conducted once, and the results were compared with those of the control group. Fetal Doppler examination for peripheral circulation was conducted weekly before 36 weeks and twice a week after that until delivery in the ICP group, and the results were compared with the reference range consistent with gestational age (17). Thus, 72 Doppler readings were taken from 22 patients with ICP at scheduled intervals during the study period.

Figure 1 represents a flow chart of the study design.

\section{Statistical analysis}

Depending on the distribution of the measured values, Student's t test (data normally distributed) or Mann-Whitney U-test (data 


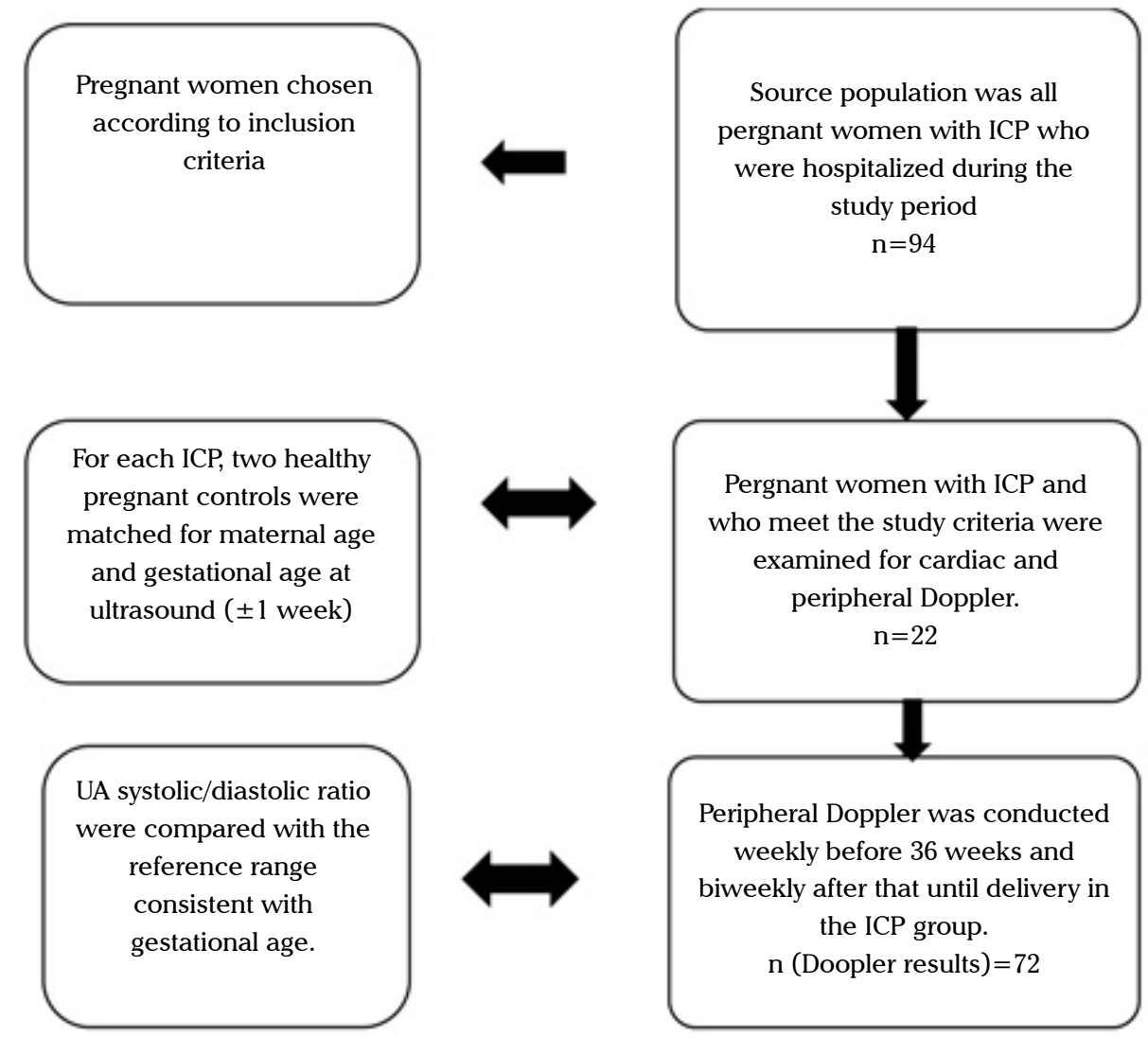

Figure 1. A flow chart of the study design

ICP: intrahepatic cholestasis of pregnancy; UA: umbilical artery

not normally distributed) were used to compare data between the fetuses with ICP mothers and normal control groups using MedCalc Version 9.3.1 (MedCalc Inc., Mariakerke, Belgium). Normal distribution of the continuous variables was assessed with the Kolmogorov-Smirnov test. $\mathrm{P}<0.05$ was considered statistically significant.

\section{Results}

Totally, 66 pregnant women were included in this study; 22 pregnant women who had ICP comprised the ICP group and 44 women without ICP comprised the control group. The mean maternal age was $26.4 \pm 5.5$ years and $27.6 \pm 4.8$ years for the ICP group and control group, respectively. The median gestational age was 34.7 (29-40) weeks and 33.5 (31-38) weeks for the ICP group and control group, respectively. There were no significant differences in maternal age, gestational age, and gravida and parity between the two groups. The mean serum AST level at diagnosis was 138.90 $\pm 97.6 \mathrm{IU} / \mathrm{L}$ (range 41-477IU/L); the mean serum ALT level was 154.62 \pm 104.2 IU/L (range 39-498 IU/L) in the study group. The demographic characteristics of both groups are shown in Table 1.
There was no statistically significant difference in the E/A ratio for each $\mathrm{AV}$ valve in the aorta and pulmonary artery peak systolic velocities and IAo PSV values between the study and control groups. Additionally, there were no significant differences in pulmonary vein PI and PVI values between the study and control groups. Doppler-derived fetal cardiac measurements are shown in Table 2 .

There was no statistically significant difference in the UA and MCA Doppler S/D ratio, PI, and RI. Obstetric Doppler measurements are shown in Table 3.

When the findings were compared with the reference values of Doppler flow velocities of UA of a normal pregnant population, it was found that the $S / D$ ratio readings were significantly above 2 SD before 35 weeks of gestation (Table 4).

No episode of fetal asphyxia or bradycardia was observed. The overall rate of meconium passage was $27.2 \%(6 / 22)$ in the ICP group $(\mathrm{p}<0.01)$. Spontaneous preterm birth was observed in $18.1 \%(4 / 22)$ of the ICP mothers. The mean gestational age was 39.1 weeks in the control group and 36.4 weeks in the ICP group $(\mathrm{p}<0.01)$. The mean birthweight was $3460.5 \mathrm{~g}$ in the control group and $2987.2 \mathrm{~g}$ in the ICP group $(\mathrm{p}<0.01)$. The cesarean delivery rate was $54.5 \%(12 / 22)$ in the ICP group. The median 
Table 1. Characteristics of the study group

\begin{tabular}{|l|c|c|c|}
\hline $\begin{array}{l}\text { Clinical } \\
\text { characteristics }\end{array}$ & $\begin{array}{c}\text { Control group } \\
\mathbf{n = 4 4}\end{array}$ & $\begin{array}{c}\text { ICP group } \\
\mathbf{n = 2 2}\end{array}$ & $\mathbf{p}$ \\
\hline Age (years) & $27.6 \pm 4.8$ & $26.4 \pm 5.5$ & 0.4 \\
\hline Parity & $1.8 \pm 0.9$ & $1.8 \pm 0.9$ & 0.9 \\
\hline $\begin{array}{l}\text { Gestational age at } \\
\text { examination (weeks) }\end{array}$ & $33.5 \pm 3.2$ & $34.7 \pm 3.4$ & 0.06 \\
\hline ALT (IU/L) & $22.1 \pm 3.4$ & $154.62 \pm 104.2$ & $<0.01$ \\
\hline AST (IU/L) & $24.6 \pm 2.8$ & $138.90 \pm 97.6$ & $<0.01$ \\
\hline Data are presented as & & & \\
\hline
\end{tabular}

Data are presented as mean \pm standard deviation. $\mathrm{P}<0.05$ was considered statistically significant.

ICP: intrahepatic cholestasis of pregnancy; ALT: alanine aminotransferase; AST: aspartate aminotransferase

Table 2. Mean Doppler index values of $\mathrm{Ao}, \mathrm{Pa}, \mathrm{Pv}$, tricuspid and mitral valves in ICP and healty pregnancies

\begin{tabular}{|l|c|c|c|}
\hline $\begin{array}{l}\text { Cardiac } \\
\text { parameters }\end{array}$ & $\begin{array}{c}\text { Control group } \\
\mathbf{n = 4 4}\end{array}$ & $\begin{array}{c}\text { ICP group } \\
\mathbf{n = 2 2}\end{array}$ & $\mathbf{p}$ \\
\hline Pa-PVI & $76.2 \pm 11$ & $82.5 \pm 13.1$ & 0.09 \\
\hline Ao-PVI & $88.7 \pm 14.1$ & $90.4 \pm 12.3$ & 0.51 \\
\hline Pv-PI & $1.01 \pm 0.1$ & $1.02 \pm 0.2$ & 0.69 \\
\hline Pv-PVI & $0.70 \pm 0.1$ & $0.72 \pm 0.1$ & 0.84 \\
\hline TV-E/A & $0.75 \pm 0.1$ & $0.74 \pm 0.1$ & 0.94 \\
\hline MV-E/A & $0.76 \pm 0.1$ & $0.79 \pm 0.1$ & 0.25 \\
\hline IAo-PSV & $104.01 \pm 14.3$ & $108.6 \pm 15.4$ & 0.36 \\
\hline
\end{tabular}

Data are presented as mean \pm standard deviation. $\mathrm{P}<0.05$ was considered statistically significant.

ICP: intrahepatic cholestasis of pregnancy; Pa-PVI: pulmonary artery peak velocity index; Ao-PVI: aortic peak velocity index; Pv-PI: pulmonary vein pulsatility index; Pv-PVI: pulmonary vein peak velocity index; MV: mitral valve; TV: tricuspid valve; E/A: E- and A- wave peak velocity ratio; IAo-PSV: isthmus aortic peak systolic velocity

Table 3. Mean Doppler index values of umbilical and middle cerebral arteries in ICP and healthy pregnancies

\begin{tabular}{|l|c|c|c|}
\hline $\begin{array}{l}\text { Fetal Doppler } \\
\text { parameters }\end{array}$ & $\begin{array}{c}\text { Control group } \\
\mathbf{n = 4 4}\end{array}$ & $\begin{array}{c}\text { ICP group } \\
\mathbf{n = 2 2}\end{array}$ & $\mathbf{p}$ \\
\hline MCA-PI & $1.77 \pm 0.4$ & $2.56 \pm 4.3$ & 0.48 \\
\hline MCA-RI & $0.80 \pm 0.08$ & $0.78 \pm 0.08$ & 0.39 \\
\hline MCA-SD & $6.1 \pm 2.9$ & $5.4 \pm 2.4$ & 0.35 \\
\hline UA-PI & $0.89 \pm 0.14$ & $0.92 \pm 0.17$ & 0.40 \\
\hline UA-RI & $0.59 \pm 0.06$ & $0.60 \pm 0.07$ & 0.31 \\
\hline UA-S/D & $2.53 \pm 0.45$ & $2.64 \pm 0.49$ & 0.32 \\
\hline
\end{tabular}

Data are presented as mean \pm standart deviation. $\mathrm{P}<0.05$ was considered statistically significant.

ICP: intrahepatic cholestasis of pregnancy; MCA: middle cerebral artery; PI: pulsatility index; RI: resistance index; S/D: systole/diastole; UA: umbilical artery

Apgar score was 8 at $1 \mathrm{~min}$ and 9 at $5 \mathrm{~min}$. None of the newborns had an Apgar score $<7$ at 5 min (Table 5).

\section{Discussion}

In this study, we examined fetal cardiac and systemic circulation using routine echocardiographic Doppler parameters which may add information regarding fetal circulatory dynamics in women who have ICP.

Bile acids and their toxic metabolic by products are implicated for fetal morbidity associated with ICP. In animal models, bile acids may exert toxic effects on the myometrium and placenta. Elevated serum taurocholate, a bile acid within the fetus, may contribute to fetal dysrhythmia and intrauterine mortality. Taurocholate may impair the propagation of cardiac conduction and disrupt synchronous contraction via the interruption of calcium dynamics of the cardiomyocytes and alter the function of the gap junctions $(8,9)$. In another experimental animal study, investigators evaluated the influence of tauro-conjugated cholic acid administration on in vitro cultures of adult and neonatal rat cardiomyocytes and reported that neonatal rat cardiomyoctes are more sensitive to adverse effects, including altered calcium dynamics, arrhythmias, and abnormal contraction, of bile acids relative to adult cardiomyocytes (18). These data are consistent with the observation that pregnant women with ICP do not have arrhythmia and cardiotoxic effects. It is not possible to investigate the effects of bile acids on the intact human fetal heart at a cellular level. However, it is postulated that if elevated bile acids are toxic on the fetal heart, there may be alterations in cardiac circulation and cardiac Doppler measurements.

In our study, we aimed to evaluate the fetal cardiac function using relatively simple Doppler measurements, which do not require special training and equipment. Based on this idea, we performed Doppler analysis to assess the diastolic function of the fetal heart using the E/A ratio of both mitral and tricuspid valves and pulmonary vein PI and PVI. Changes observed in pulmonary vein flow velocity indicate left atrial pressure dynamics occurring during the cardiac cycle (19). Peak flow velocities of the aorta and pulmonary artery in pulsed Doppler pattern were evaluated for the systolic function of the heart. Additionally, for investigating the balance between both ventricular outputs and differences in the impedance of both vascular systems, we performed aortic isthmus Doppler. We found no difference in the fetal cardiac and peripheral Doppler parameters between the two groups. A recent study evaluated fetal echocardiographic examinations of fetuses in pregnant women who have ICP (20). The researchers reported that the left ventricular longitudinal strain, systolic strain rate, and diastolic strain rate are significantly decreased in fetuses with severe cholestasis compared with those in control fetuses. Furthermore, there was a positive correlation between fetal myocardial deformation and maternal total bile acid levels.

Maternal prognosis is excellent in ICP, but there are significant risks for the fetus. We observed that both spontaneous and iatrogenic preterm labor, meconium-stained amniotic fluid, and neonatal unit admission ratio in the ICP group were significantly high than those in the control group. There are limited data regarding the association between obstetric Doppler and abnormal fetal outcome in women who had ICP. Guerra et al. (21) concluded that there are no significant changes in any of the blood flow velocity indices determined by Doppler blood flow analysis in patients with obstetric cholestasis. Zimmermann et al. (22) determined the Pourcelot ratio in affected pregnancies with obstetric cholestasis and found Doppler to be of little value 
Table 4. Mean systolic/diastolic ratio of the umbilical artery in the ICP group for gestational week

\begin{tabular}{|c|c|c|c|c|c|}
\hline $\begin{array}{l}\text { Gestational } \\
\text { week }\end{array}$ & $\begin{array}{c}\text { Systolic/diastolic } \\
\text { ratio in ICP group } \\
\text { (mean } \pm \text { SD) }\end{array}$ & $\begin{array}{c}50^{\text {th }} \\
\text { percentile }\end{array}$ & $\begin{array}{c}95^{\text {th }} \\
\text { percentile }\end{array}$ & $\begin{array}{l}\mathrm{S} / \mathrm{D} \text { ratio readings } \\
\text { were above } 2 \mathrm{SD}(\mathrm{n}, \%)\end{array}$ & $\mathbf{p}$ \\
\hline $33-34$ & $3.52 \pm 1.1$ & 2.52 & 3.68 & $3 / 7(42.8)$ & 0.01 \\
\hline $34-35$ & $3.26 \pm 0.9$ & 2.46 & 3.58 & $9 / 25(36)$ & 0.04 \\
\hline $35-36$ & $2.71 \pm 0.7$ & 2.39 & 3.49 & $4 / 28(14.2)$ & 0.09 \\
\hline $36-37$ & $2.69 \pm 0.9$ & 2.34 & 3.41 & $1 / 12(8.3)$ & 0.6 \\
\hline \multicolumn{6}{|c|}{$\begin{array}{l}\text { In total, seventy-two Doppler results were evaluated. } \mathrm{P}<0.05 \text { was considered statistically significant. } \\
\text { Data are presented as mean } \pm \text { standard deviation. } \\
\text { ICP: intrahepatic cholestasis of pregnancy; S/D: systole/diastole }\end{array}$} \\
\hline
\end{tabular}

Table 5. Perinatal outcomes of intrahepatic cholestasis of pregnancy (ICP) and healthy pregnancies

\begin{tabular}{|l|c|c|c|}
\hline $\begin{array}{l}\text { Perinatal outcomes of } \\
\text { of ICP and healthy } \\
\text { pregnancies }\end{array}$ & $\begin{array}{c}\text { Control } \\
\text { group } \\
\mathbf{n = 4 4}\end{array}$ & $\begin{array}{c}\text { ICP } \\
\text { group } \\
\mathbf{n = 2 2}\end{array}$ & $\mathbf{p}$ \\
\hline $\begin{array}{l}\text { Mean ( } \pm \text { SD) gestational age } \\
\text { at delivery (weeks) }\end{array}$ & $39.1(1.2)$ & $36.4(1.5)$ & $<0.01$ \\
\hline Preterm delivery (n, \%) & $4,9 \%$ & $8,36.3 \%$ & $<0.01$ \\
\hline Spontaneous <37 weeks & $1,2.2 \%$ & $4,18.1 \%$ & $<0.01$ \\
\hline Iatrogenic <37 weeks & $3,6.8 \%$ & $4,18.1 \%$ & $<0.01$ \\
\hline $\begin{array}{l}\text { Mode of delivery cesarean } \\
\text { section (n, \%) }\end{array}$ & $18,40.9 \%$ & $12,54.5 \%$ & 0.05 \\
\hline Birthweight (g) & 3460.5 & 2987.2 & 0.04 \\
\hline Stillbirth & - & - & - \\
\hline 5 min Apgar $\leq 7$ (n, \%) & - & - & - \\
\hline Neonatal unit admission (n, \%) & $2,4.5 \%$ & $4,18.1 \%$ & 0.04 \\
\hline $\begin{array}{l}\text { Meconium-stained amniotic } \\
\text { fluid (n, \%) }\end{array}$ & 0 & $6,27.2 \%$ & $<0.01$ \\
\hline $\begin{array}{l}\text { P<0.05 was considered statistically significant. } \\
\text { ICP: intrahepatic cholestasis of pregnancy; SD: standard deviation }\end{array}$ \\
\hline
\end{tabular}

in studying the disease-specific risk of fetal compromise. Suri et al. (23) found that there are some alterations in UA Doppler parameters in pregnancies complicated by ICP compared with those in the normal range, but Doppler parameters do not correlate with the severity of disease and rates of preterm delivery or meconium-stained liquor. Doppler measurements of the fetal UA and MCA did not differ between the two groups in our study. S/D ratio readings in the ICP group were significantly above 2 SD before 35 weeks of gestation. Based on this data, it is claimed that the Doppler measurement of UA is useful in the monitoring of early onset intrahepatic cholestasis.

The present study has several important limitations. First, the study group was limited to a small group of women; future studies will require a broader and more diverse study pool. Second, the patients were evaluated for cardiac circulation only once, and serial measurements may have revealed additional insights. Furthermore, all women who have ICP were treated with UDCA, which may modify the course of the disease.

In summary, sudden fetal death in women who have ICP is an important problem that remains poorly understood. Women who have obstetric cholestasis do not exhibit Doppler alterations in fetal cardiac or systemic circulation. Further prospective studies with larger series are needed for defining fetal cardiac function in women who have ICP.

Ethics Committee Approval: Ethics committee approval was received for this study from the ethics committee of Aegean Maternity and Teaching Hospital.

Informed Consent: Written informed consent was obtained from patients who participated in this study.

Peer-review: Externally peer-reviewed.

Author Contributions: Concept - S.K., E.B.G.; Design - E.B.G.; Supervision - E.B.G.; Resource - E.Sु.G.; Materials - D.Ö., D.O., I.G.; Data Collection \& /or Processing - D.Ö., D.O., I.G., E.Sु.G.; Analysis \& /or Interpretation - E.B.G., S.K.; Literature Search E.B.G.; Writing - E.B.G., S.K.; Critical Reviews - E.B.G., S.K.

Conflict of Interest: No conflict of interest was declared by the authors.

Financial Disclosure: The authors declared that this study has received no financial support.

\section{References}

1. Reyes $\mathrm{H}$. The enigma of intrahepatic cholestasis of pregnancy: lessons from Chile. Hepatology 1982; 2: 87-96. [CrossRef]

2. Fisk NM, Storey GNB. Fetal outcome in obstetric cholestasis. Br J Obstet Gynaecol 1988; 95: 1137-43. [CrossRef]

3. Rioseco AJ, Ivankovic MB, Manzur A, Hamed F, Kato SR, Parer JT, Germain AM. Intrahepatic cholestasis of pregnancy: a retrospective case-control study of perinatal outcome. Am J Obstet Gynecol 1994; 170: 890-5. [CrossRef]

4. Lee RH, Incerpi MH, Miller DA, Pathak B, Goodwin TM. Sudden fetal death in intrahepatic cholestasis of pregnancy. Obstet Gynecol 2009; 113: 528-31. [CrossRef]

5. Laatikainen TJ, Tulenheimo A. Maternal serum bile acid levels and fetal distress in cholestasis of pregnancy. Int $\mathrm{J}$ Gynaecol Obstet 1984; 22: 91-4. [CrossRef]

6. Glantz A, Marschall HU, Mattsson LA. Intrahepatic cholestasis of pregnancy: Relationships between bile acid levels and fetal complication rates. Hepatology 2004; 40: 467-74. [CrossRef]

7. Lee RH, Kwok KM, Ingles S, Wilson ML, Mullin P, Incerpi M, et al. Pregnancy outcomes during an era of aggressive management for intrahepatic cholestasis of pregnancy. Am J Perinatol 2008; 25: 341-5. [CrossRef] 
8. Williamson C, Gorelik J, Eaton BM, Lab M, de Swiet M, Korchev Y. The bile acid taurocholate impairs rat cardiomyocyte function: a proposed mechanism for intra-uterine fetal death in obstetric cholestasis. Clin Sci (Lond) 2001; 100: 363-9. [CrossRef]

9. Williamson C, Miragoli M, Sheikh Abdul Kadir S, Abu-Hayyeh S, Papacleovoulou G, Geenes V, Gorelik J. Bile acid signaling in fetal tissues: implications for intrahepatic cholestasis of pregnancy. Dig Dis 2011; 29: 58-61. [CrossRef]

10. Al Inizi S, Gupta R, Gale A. Fetal tachyarrhythmia with atrial flutter in obstetric cholestasis. Int J Gynaecol Obstet 2006; 93: 53-4. [CrossRef]

11. Zhang $\mathrm{K}$, Wang $\mathrm{Z}$. Clinical value of fetal monitoring in intrahepatic cholestasis of pregnancy. Zhonghua Fu Chan Ke Za Zhi 2000; 35 : 23-5.

12. Alsulyman OM, Ouzounian JG, Ames-Castro M, Goodwin TM. Intrahepatic cholestasis of pregnancy: perinatal outcome associated with expectant management. Am J Obstet Gynecol 1996; 175: 957-60. [CrossRef]

13. Sheibani L, Uhrinak A, Lee RH, Fong A, Pathak B. Intrahepatic cholestasis of pregnancy: the effect of bile acids on fetal heart rate tracings. Obstet Gynecol 2014; 123: 78S-9S. [CrossRef]

14. Martinez E, Rodriguez N, Lisoni M, Cruzat L, Glasinovic J, Marinovic I.Usefulness of biophysical profile in intrahepatic cholestasis of pregnancy. Rev Chil Obstet Ginecol 1987; 52: 137-41.

15. Bacq Y, Sapey T, Brechot MC, Pierre F, Fignon A, Dubios F. Intrahepatic cholestasis of pregnancy: a French prospective study. Hepatology 1997; 26: 358-64. [CrossRef]

16. Heikkinen J, Maentausta O, Ylostalo P, Janne O. Changes in serum bileacid concentrations during normal pregnancy, in patients with intrahepatic cholestasis of pregnancy and in pregnant women with itching. Br J Obstet Gynaecol 1981; 88: 240-5. [CrossRef]

17. Acharya G, Wilsgaard T, Berntsen GK, Maltau JM, Kiserud T. Reference ranges for serial measurements of umbilical artery Doppler indices in the second half of pregnancy. Am J Obstet Gynecol 2005; 192: 937-44. [CrossRef]

18. Sheikh Abdul Kadir SH, Ali NN, Brito-Martins M, Abu-Hayyeh S, Moshkov AV, Williamson C, et al. Embryonic stem cell-derived cardiomyocytes as a model to study fetal arrhythmia related to maternal disease. J Mol Cell Med 2009; 13: 3730-41. [CrossRef]

19. Zielinsky P, Piccoli AL Jr, Teixeira L, Gus EI, Mânica JL, Satler F, et al. Pulmonary vein pulsatility in fetuses of diabetic mothers: prenatal Doppler echocardiographic study. Arq Bras Cardiol 2003; 81: 604-7, 600-3. Epub 2004 Jan 28.

20. Fan X, Zhou Q, Zeng S, Zhou J, Peng Q, Zhang M, Ding Y. Impaired fetal myocardial deformation in intrahepatic cholestasis of pregnancy. J Ultrasound Med 2014; 33: 1171-7. [CrossRef]

21. Guerra F, Guzman S, Campos G. Evaluation of maternal and fetal blood flow indices in intrahepatic cholestasis of pregnancy. Rev Chil Obstet Ginecol 1994; 59: 17-21.

22. Zimmermann P, Koskinen J, Vaalamo P, Ranata T. Doppler umbilical artery velocimetry in pregnancies complicated by intrahepatic cholestasis. J Perinat Med 1991; 19: 351-5. [CrossRef]

23. Suri V, Jain R, Aggarwal N, Chawla YK, Kohli KK. Usefulness of fetal monitoring in intrahepatic cholestasis of pregnancy: a prospective study. Arch Gynecol Obstet 2012; 286: 1419-24. [CrossRef] 